\title{
The Hajj: updated health hazards and current recommendations for 2012
}

J A Al-Tawfiq ${ }^{1}$, Z A Memish (zmemish@yahoo.com)2

1. Saudi Aramco Medical Services Organization, Dhahran, Kingdom of Saudi Arabia

2. Public Health Directorate, Ministry of Health, Riyadh, Director WHO Collaborating Center for Mass Gathering Medicine, Professor, College of Medicine, Alfaisal University, Riyadh, Kingdom of Saudi Arabia

This year the Hajj will take place during 24-29 October. Recent outbreaks of Ebola haemorrhagic fever in Uganda and the Democratic Republic of the Congo, cholera in Sierra Leone, and infections associated with a novel coronavirus in Saudi Arabia and Qatar required review of the health recommendations of the 2012 Hajj. Current guidelines foresee mandatory vaccination with quadrivalent meningococcal vaccine for all pilgrims, and yellow fever and poliomyelitis vaccine for pilgrims from high-risk countries. Influenza vaccine is strongly recommended.

The annual Hajj is one of the greatest assemblies of humankind on earth. Each year, three million Muslims attend the Hajj in Mecca, Saudi Arabia. Of these, 1.8 million non-Saudi Arabians usually come from overseas countries and $89 \%$ (1.6 millions) of them arrive by air [1]. Pilgrims come from more than 180 countries worldwide and about 45,000 pilgrims each year arrive to Saudi Arabia from the European Union [2].

\section{Preventive measures during the Hajj}

Saudi Arabia provides free healthcare to all pilgrims during the Hajj. For the $2012 \mathrm{Hajj}$, which will take place on 24-29 October 2012, the country has prepared 25 hospitals, 4,427 beds including 500 critical care beds and 550 emergency care beds. In addition, there are 141 healthcare centres in the vicinity of the Hajj area with 20,000 specialised healthcare workers. The planning for the Hajj relies on the coordinated efforts of 24 supervisory committees [2]. The Hajj preventive medicine committee oversees all public health and preventative matters during the Hajj. A large number of public health officers regulate ports of entry for all pilgrims to ensure compliance with the requirements of the Saudi Arabian Ministry of Health. Public health teams are located in various areas of the Hajj, including 21 mobile teams. At each of the 18 hubs at King Abdulaziz International Airport Hajj terminal in Jeddah, two clinical examination rooms and a large holding area are dedicated to assess arriving pilgrims, check their immunisation status, and administer the recommended prophylactic medicines [2]. The public health teams and teams at the ports of entry report back to the command centre on nine communicable diseases using electronic and manual surveillance systems. These diseases are influenza, influenza-like illness, meningococcal disease, food poisoning, viral haemorrhagic fevers, yellow fever, cholera, poliomyelitis, and plague [2].

\section{Pre- and post-Hajj travel advice}

The Hajj is a unique event with possible impact on international public health. Healthcare practitioners around the world must be attentive to the potential risks of disease transmission during the Hajj. They must recommend appropriate strategies for the prevention and control of communicable diseases before, during and after the completion of the Hajj. The current international collaboration in planning vaccination campaigns, developing visa quotas, arranging rapid repatriation, and managing health hazards at the Hajj are crucial steps in this process. The Saudi Arabian Ministry of Health publishes the Hajj requirements for each Hajj season. This year's Hajj recommendations have recently been published [3].

Recent outbreaks of Ebola haemorrhagic fever in Uganda and the Democratic Republic of the Congo (DRC), cholera in Sierra Leone, and infections associated with a novel coronavirus in Saudi Arabia and Qatar required review of the health recommendations of the 2012 Hajj. We present here the changes and additions made in the recommendations for these diseases. For completeness, we also summarise the existing recommendations $[3,4]$.

\section{Meningococcal disease}

The risk of the occurrence of meningococcal outbreaks is a real concern during the Hajj seasons. This risk is related to the high carriage rates with one study from Mecca reporting carriage rate as high as $80 \%$ [5]. Due to the previous occurrence of meningococcal outbreaks, the bivalent $A$ and $C$ meningococcal vaccine became a requirement for the attendance of the Hajj in 1986. Two large outbreaks caused by meningococcal 
serogroup $W_{135}$ in 2000 and 2001 [6-8] resulted in an extension of the previous requirement to include serogroups $Y$ and $W_{135}$, and the quadrivalent $(A, C$, $Y$, W135) meningococcal polysaccharide vaccine was included as a requirement for a Hajj visa in May 2001 [9]. In addition, visitors arriving from countries in the African meningitis belt receive chemoprophylaxis with ciprofloxacin tablets $(500 \mathrm{mg})$ at the port of entry to lower the rate of meningococcal carriage. It is estimated that about 400,000 to 460,000 pilgrims receive the recommended doses at the port of entry in Saudi Arabia. Compliance with meningococcal vaccination among arriving international pilgrims exceeded $97 \%$ in 2011 [1].

\section{Yellow fever}

In accordance with the International Health Regulations 2005, all travellers arriving from countries identified by the World Health Organization (WHO) as areas at risk of yellow fever must present a valid yellow fever vaccination certificate showing that the person was vaccinated at least 10 days previously and not more than 10 years before arrival at the border. In the absence of such a certificate, the individual will be placed under strict surveillance for six days from the date of vaccination or the last date of potential exposure to infection, whichever is earlier. Health offices at entry points will be responsible for notifying the appropriate Director General of Health Affairs in the region or governorate about the temporary place of residence of the visitor. Aircrafts, ships and other means of transportation arriving from countries affected by yellow fever are requested to submit a certificate indicating that it applied disinfection in accordance with methods recommended by the WHO.

\section{Risks of respiratory tract infections}

Acute upper respiratory tract infections (URTIs) are the most common disease during Hajj. There are many factors promoting the spread of respiratory pathogens, including close contact among pilgrims, shared sleeping tents and dense air pollution [2]. The pathogens causing URTIs among pilgrims are respiratory syncytial virus (RSV), parainfluenza virus, influenza virus and adenovirus [10]. The rates of different types of respiratory virus infections are as follows: influenza (9.8\%), parainfluenza (7.4\%), adenovirus (5.4\%) and RSV (1.4\%) [11]. Because of overcrowding and the fact that many Muslims come from countries where tuberculosis (TB) is endemic, pulmonary tuberculosis was a leading cause of hospitalisation in patients with community-acquired pneumonia [12]. The estimated risk of tuberculosis acquisition during the Hajj is thought to be around $10 \%$, based on the use of pre-visit and postvisit QuantiFERON TB assay test [13]. In another community-based survey of the epidemiology of tuberculosis in Saudi Arabia, positive tests using purified tuberculin antigens were more frequent in Saudi Arabians living in the Holy cities hosting pilgrims compared to other cities in Saudi Arabia [14]. The development of strategies to reduce the transmission of TB during the Hajj is a challenge for which no evidence-based approved measures are available to date. The Saudi Arabian Ministry of Health continues to recommend wearing face mask in crowded places and changing them frequently to minimise transmission of respiratory infections. Controlling tuberculosis transmission in mass gatherings is an area that needs urgent research studies. [14].

\section{Novel coronavirus infection}

Of particular interest is the recent report of two cases of acute respiratory failure associated with a novel coronavirus. Both patients were previously healthy adults. The cases occurred a few months before the 2012 Muslim Hajj season. The first case of infection with the novel coronavirus was identified in a Saudi Arabian national, who died in June $2012[15,16]$. The second case was a patient from Qatar who was transferred to a hospital in London, United Kingdom in early September 2012 [17]. Available data to date do not support humanto-human transmission of this novel coronavirus, and zoonotic transmission is highly suspected. In the second case of this novel coronavirus infection, none of the 64 close contacts developed severe disease, 13 of them $(20 \%)$ reported mild respiratory symptoms, and the novel coronavirus was not detected in 10 symptomatic contacts who were tested [17].

The WHO does not recommend any travel restrictions to or from Saudi Arabia. The current case definitions from the WHO [18] and from the Saudi Arabian Ministry of Health can be found on the WHO website (http:// www.who.int/csr/disease/coronavirus_infections/ case_definition/en/index.html) and in Table 1, respectively. The practice of good hand hygiene and cough etiquette was associated with less respiratory illness among United States travellers to the 2009 Hajj [19]. It is recommended that pilgrims continue to practice proper hand hygiene, protective behaviours and cough etiquette to further decrease the occurrence of respiratory diseases.

\section{Food-borne diseases and cholera}

Diarrhoeal illnesses during mass gathering including Hajj are a potential health hazard. Many factors may contribute to this problem including: inadequate standards of food hygiene, shortage of water, the presence asymptomatic carriers of pathogenic bacteria, and the preparation of large numbers of meals poorly stored by pilgrims. There are only few studies describing the incidence and aetiology of traveller's diarrhoea during the Hajj. In one study, diarrhoea was the third most common cause $(6.7 \%)$ of hospitalisation [20]. Another study describes an outbreak of diarrhoeal illness in a small number of soldiers during the Hajj season [21]. As a precautionary measure the Saudi Arabian Ministry of Health strongly enforces that pilgrims are not allowed to bring fresh food into Saudi Arabia. Only properly canned or sealed food or food stored in containers with easy access for inspection is allowed in 
Severe respiratory disease associated with novel coronavirus: case definition by the Saudi Arabian Ministry of Health

\begin{tabular}{|l|l|l|l|}
\hline & Clinical definition & Epidemiological criteria & Laboratory data \\
\hline Suspected case & $\begin{array}{l}\text { A person requiring hospitalisation with community- } \\
\text { acquired acute respiratory syndrome } \\
\text { Symptoms include: fever }\left(\geq 38^{\circ} \mathrm{C}\right) \text { and cough, with } \\
\text { confirmed lower airway involvement (clinical and } \\
\text { radiological evidence of pneumonia) not explained by } \\
\text { any other infection or other aetiology. }\end{array}$ & None & None \\
\hline Confirmed case & As for suspected case & $\begin{array}{l}\text { A person with laboratory- } \\
\text { confirmed infection with the } \\
\text { novel coronavirus }\end{array}$ \\
\hline
\end{tabular}

small quantities, sufficient for one person for the duration of their trip.

Cholera is another risk during the Hajj, especially in light of the continued occurrence of outbreaks in different countries. As of 20 September 2012, a total of 19,283 cases, including $276(1.4 \%)$ deaths have been reported in the ongoing cholera outbreak in Sierra Leone since the beginning of the year [22]. The highest numbers of cases occurred in the Western area of the country where the capital city of Freetown is located. In addition, the WHO reported a sharp increase in the number of cholera cases in July in the DRC and many other countries [23]. The Ministry of Health of Saudi Arabia has updated its public health staff at all ports of entry for pilgrims, to be observant of all pilgrims coming from areas where cholera has been reported by WHO, and to maintain a high level of vigilance for any signs and symptoms of diarrhoea, and to continue surveillance at their camps and initiate quarantine and contact tracing once a case is suspected. Emphasis is being placed on early detection of cases and timely provision of treatment at all Hajj premises, once pilgrims have passed the ports of entry while incubating the disease.

\section{Poliomyelitis}

Poliomyelitis is still predominant in certain countries around the world. The attendance of visitors from these countries to the Hajj may pose a health risk for other visitors. All travellers arriving from polioendemic countries and re-established transmission countries, namely Afghanistan, Angola, Chad, the DRC, Nigeria and Pakistan, regardless of age and vaccination status, should receive one dose of oral poliovirus vaccine (OPV). Proof of OPV vaccination at least six weeks prior departure is required to apply for entry visa for Saudi Arabia. These travellers will also receive one dose of OPV at borders points on arrival in Saudi Arabia. The same requirements are valid for travellers from recently endemic countries at high risk of reimportation of poliovirus, i.e. India (Table 2).

Polio cases secondary to wild poliovirus importation or to circulating vaccine-derived poliovirus in the past 12 months have been reported in the following countries: China, Central African Republic, Côte d'Ivoire, Kenya, Mali, Niger, Somalia and Yemen [4]. All visitors aged under 15 years travelling to Saudi Arabia from these countries should be vaccinated against poliomyelitis with the OPV or inactivated poliovirus vaccine (IPV). Proof of OPV or IPV vaccination six weeks prior to application is required for entry visa. Irrespective of previous immunisation history, all visitors under 15 years arriving in Saudi Arabia will also receive one dose of OPV at border points (Table 2).

\section{Ebola outbreaks}

Two large outbreaks of Ebola have been reported by the Ministries of Health of Uganda and the DRC. In Uganda, a total of 24 probable and confirmed cases were reported during the outbreak. Eleven of these 24 cases have been laboratory-confirmed by the Uganda Virus Research Institute in Entebbe. A total of 17 deaths were reported in this outbreak. The last confirmed case was admitted on 3 August 2012 and discharged from hospital on 24 August 2012 [24,25]. This is twice the maximum incubation period ( 21 days) for Ebola proposed by the WHO during Ebola outbreak response operations. In the DRC, 46 cases (14 laboratory-confirmed, 32 probable) of Ebola haemorrhagic fever were reported until 15 September 2012. Of these, 19 have been fatal (six confirmed, 13 probable). The cases occurred in two health zones of Isiro and Viadana in Haut-Uélé district in Province Orientale. Additionally, 26 suspected cases have been reported and are being investigated.

The two Ebola outbreaks are not epidemiologically linked and have been caused by two different Ebola subtypes: Ebola subtype Sudan in Uganda, and Ebola 
TABLE 2

Saudi Arabian health requirements and recommendations for entry visas for the Hajj seasons in 2012

\begin{tabular}{|c|c|c|}
\hline & Countries or areas at risk & Requirement \\
\hline Yellow fever & $\begin{array}{l}\text { Africa: } \\
\text { Angola, Benin, Burkina Faso, Burundi, Cameroon, } \\
\text { Central African Republic, Chad, Congo, Cote d’Ivoire, } \\
\text { Democratic Republic of the Congo, Equatorial Guinea, } \\
\text { Ethiopia, Gabon, Guinea, Guinea-Bissau, Gambia, } \\
\text { Ghana, Kenya, Liberia, Mali, Mauritania, Niger, Nigeria, } \\
\text { Rwanda, Senegal, Sierra Leone, Sudan, South Sudan, } \\
\text { Togo and Uganda } \\
\text { South and Central America: } \\
\text { Argentina, Venezuela, Brazil, Colombia, Ecuador, } \\
\text { French Guiana, Guyana, Panama, Paraguay, Peru, } \\
\text { Bolivia, Suriname, and Trinidad and Tobago }\end{array}$ & $\begin{array}{l}\text { A valid yellow fever vaccination certificate (at least1o days } \\
\text { previously and less than1o years before arrival). In the } \\
\text { absence of such a certificate, the individual will be placed } \\
\text { under strict surveillance for six days from the last date of } \\
\text { potential exposure to infection. }\end{array}$ \\
\hline $\begin{array}{l}\text { Meningococcal } \\
\text { meningitis }\end{array}$ & $\begin{array}{l}\text { a) Visitors from all countries } \\
\text { b) Visitors from the African meningitis belt: } \\
\text { Benin, Burkina Faso, Cameroon, Chad, Central African } \\
\text { Republic, Côte d'Ivoire, Eritrea, Ethiopia, Gambia, } \\
\text { Guinea, Guinea-Bissau, Mali, Niger, Nigeria, Senegal } \\
\text { and Sudan } \\
\text { c) Local pilgrims and the Haji workers }\end{array}$ & $\begin{array}{l}\text { a) Certificate of vaccination with the quadrivalent } \\
\text { (ACYW135) vaccine issued not more than three years } \\
\text { previously and at least10 days before arrival in Saudi } \\
\text { Arabia } \\
\text { b) ACYW135 vaccine (as above) } \\
\text { AND } \\
\text { ciprofloxacin } 500 \text { mg chemoprophylaxis administered at } \\
\text { the port of entry } \\
\text { c) Vaccination with quadrivalent (ACYW135) vaccine is } \\
\text { required for: } \\
\text { - all citizens and residents of Medina and Mecca (not } \\
\text { vaccinated during the past three years) } \\
\text { - all citizens and residents undertaking the Hajj } \\
\text { - all Haji workers (not vaccinated in the past three years) } \\
\text { - any individual working at entry points or in direct } \\
\text { contact with pilgrims in Saudi Arabia }\end{array}$ \\
\hline Poliomyelitis & $\begin{array}{l}\text { a) Arriving from polio-endemic countries and } \\
\text { re-established transmission countries: } \\
\text { Afghanistan, Angola, Chad, the Democratic Republic of } \\
\text { Congo, India, Nigeria and Pakistan } \\
\text { b) Recently endemic countries at high risk of } \\
\text { re-importation of poliovirus: } \\
\text { India, Cameroon, Central African Republic, } \\
\text { Cote d'Ivoire, Kenya, Mali, Niger, Somalia and Yemen }\end{array}$ & $\begin{array}{l}\text { a) All travellers should receive one dose of OPV at least } \\
\text { six weeks prior to departure and will receive one dose } \\
\text { of OPV at the border on arrival to Saudi Arabia. } \\
\text { b) All visitors under } 15 \text { years of age should receive one } \\
\text { dose of oral polio vaccine (OPV) at least six weeks prior } \\
\text { to departure and will receive one dose of OPV at the } \\
\text { border on arrival to Saudi Arabia. }\end{array}$ \\
\hline Seasonal influenza & All & $\begin{array}{l}\text { The Ministry of Health of Saudi Arabia recommends that } \\
\text { all pilgrims be vaccinated against seasonal influenza }\end{array}$ \\
\hline
\end{tabular}

OPV: oral polio vaccine. 
subtype Bundibugyo in DRC. To avoid global spread of the disease, the Saudi Arabian Ministry of Health decided to exclude pilgrims from these two countries for this Hajj season. This restriction is based on the careful review and deliberation of the national committee on communicable disease prevention who felt that it cannot be excluded that new cases may emerge, and on the fact that the risk of disease transmission is thought to be high with potential catastrophic consequences if occurring during the Hajj, as the disease has a high mortality rate and no therapeutic interventions are available.

\section{References}

1. Al-Tawfiq JA and Memish ZA. Mass gatherings and infectious diseases: prevention, detection and control. Infect Dis Clin North Am. 2012;26(3):725-37.

2. Memish ZA. The Hajj: communicable and non-communicable health hazards and current guidance for pilgrims. Euro Surveill. 2010;15(39):pii=19671. Available from: http://www. eurosurveillance.org/ViewArticle.aspx?Articleld=19671

3. Memish ZA, Al Rabeeah AA. Health conditions for travellers to Saudi Arabia for the Umra and Haji pilgrimage to Mecca: Requirements for 2012 (1433). J Infect Public Health 2012; 5(2):113-5.

4. Health conditions for travellers to Saudi Arabia for the pilgrimage to Mecca (Haji). Wkly Epidemiol Rec. 2012;87(30):277-80.

5. al-Gahtani YM, el Bushra HE, al-Qarawi SM, al-Zubaidi AA, Fontaine RE. Epidemiolological investigation of an outbreak of meningococcal meningitis in makkah (Mecca), Saudi Arabia, 1992. Epidemiol Infect. 1995;115(3): 399-409.

6. Memish ZA, Venkatesh S, Ahmed QA. Travel epidemiology: the Saudi perspective. Int J Antimicrob Agents. 2003;21(2): 96-101.

7. Mayer LW, Reeves MW, Al-Hamdan N, Sacchi CT, Taha MK, Ajello GW, et al. Outbreak of W135 meningococcal disease in 2000: not emergence of a new W135 strain but clonal expansion within the electrophoretic type-37 complex. J Infect Dis 2002;185(11):1596-1605.

8. Issack MI, Ragavoodoo C. Hajj-related Neisseria meningitidis serogroup W135 in Mauritius. Emerg Infect Dis 2002;8(3):332-4.

9. Borrow R. Meningococcal disease and prevention at the Hajj. Travel Med Infect Dis. 2009(4):219-25.

10. Balkhy HH, Memish ZA, Bafaqeer S, Almuneef MA. Influenza a common viral infection among Hajj pilgrims: time for routine surveillance and vaccination. J Travel Med. 2004;11(2):82-6.

11. Alborzi A, Aelami MH, Ziyaeyan M, Jamalidoust M, Moeini $M$, Pourabbas $B$, et al. Viral etiology of acute respiratory infections among Iranian Hajj pilgrims, 2006. I Travel Med. 2009;16(4):239-42.

12. Alzeer A, Mashlah A, Fakim N, Al-Sugair N, Al-Hedaithy M, Al-Majed S, et al. Tuberculosis is the commonest cause of pneumonia requiring hospitalization during Hajj (pilgrimage to Makkah). J Infect. 1998;36(3):303-6.

13. Wilder-Smith A, Foo W, Earnest A, Paton NI. High risk of Mycobacterium tuberculosis infection during the Hajj pilgrimage. Trop Med Int Health. 2005;10(4):336-9.

14. al-Kassimi FA, Abdullah AK, al-Hajjaj MS, al-Orainey IO, Bamgboye EA, Chowdhury MN. Nationwide community survey of tuberculosis epidemiology in Saudi Arabia. Tuber Lung Dis 1993;74(4):254-60.

15. ProMED-mail. Novel coronavirus - Saudi Arabia: human isolate. Archive Number: 20120920.1302733. September 20 September 2012. Available from: http://www.promedmail. $\operatorname{org} / \mathrm{p}=2400: 1000$

16. Corman VM, Eckerle I, Bleicker T, Zaki A, Landt O, EschbachBludau $\mathrm{M}$, et al. Detection of a novel human coronavirus by real-time reverse-transcription polymerase chain reaction. Euro Surveill. 2012;17(39):pii=20285. Available from: http:// www.eurosurveillance.org/ViewArticle.aspx?Articleld $=20285$

17. Pebody RG, Chand MA, Thomas HL, Green HK, Boddington NL, Carvalho C, et al. The United Kingdom public health response to an imported laboratory confirmed case of a novel coronavirus in September 2012. Euro Surveill. 2012;17(40): pii=20292. Available from: http://www. eurosurveillance.org/ViewArticle.aspx?Articleld =20292
18. Revised interim case definition - novel coronavirus. Geneva: World Health Organization; 29 Sept 2012. Available from: http://www.who.int/csr/disease/coronavirus_infections/case definition/en/index.html

19. Balaban V, Stauffer WM, Hammad A, Afgarshe M, Abd-Alla $M$, Ahmed Q, et al. Protective practices and respiratory illness among US travelers to the 2009 Hajj. J Travel Med. 2012;19(3):163-8.

20. Al-Ghamdi SM, Akbar HO, Qari YA, Fathaldin OA, Al-Rashed RS. Pattern of admission to hospitals during muslim pilgrimage (Haji). Saudi Med J 2003;24(10):1073-6.

21. Al-Joudi AS. An outbreak of foodborne diarrheal illness among soldiers in mina during hajj: the role of consumer food handling behaviors. J Family Community Med. 2007;14(1):29-33.

22. WHO/UNICEF Sierra Leone. Cholera Situation in Sierra Leone, 21 September, 2012. Available from: http://www.afro.who.int/ index.php?option $=$ com_docman\&task $=$ doc_download\&gid $=78$ 68\&ltemid $=259323$

23. Cholera: situation in the WHO African Region, 22 August 2012. Cité du Djoué: World Health Organization Regional Office for Africa. [Accessed 4 Oct 2012]. Available from: http://www.who. int/hac/crises/cholera_afro_22august2012.pdf

24. 2012: Ebola Hemorrhagic Fever Outbreak in Democratic Republic of Congo. Outbreak Postings. Atlanta: Centers for Disease Prevention and Control (CDC). [Accessed 4 Oct 2012]. Available from: http://www.cdc.gov/ncidod/dvrd/spb/ outbreaks/index.htm\#ebola-drc-2012

25. 2012: Ebola Hemorrhagic Fever Outbreak in Uganda. Outbreak Postings. Atlanta: Centers for Disease Prevention and Control (CDC). [Accessed 4 Oct 2012]. Available from: http://www.cdc. gov/ncidod/dvrd/spb/outbreaks/index.htm\#ebola-drc-2012 